Session \# 2666

\title{
Experiential Problem Based Learning in the Mechanics of Materials Laboratory
}

\author{
Ronald U. Goulet, Ph.D., P.E., Joseph Owino, Ph.D., P.E. \\ College of Engineering and Computer Science \\ University of Tennessee at Chattanooga
}

\section{Background}

The College of Engineering and Computer Science at UT Chattanooga has reported broad efforts aimed to modernize and enhance undergraduate engineering laboratories and design courses. ${ }^{1,2,3,4,5}$. This process of improvement was recently directed to the mechanics of materials laboratory course. The College offers second year engineering students a one credit hour mechanics of materials lab concurrently with a three credit hour lecture. Historically, the lab experience consisted of demonstrations and a final truss design/build assignment. The sequence of demonstration lab topics included: hardness testing of metals, toughness testing and the Charpy impact specimen, tensile testing of metals, deflection and strain of a simply supported beam, deflection and strain of a shaft in torsion and deflection and strain of a truss. The final project required each student to analyze, construct then proof test a simply supported balsa truss of some given design.

Review and Findings

The lab improvement process began with information gathering, a review of the course content for compatibility with its co-requisite and subsequent courses in the mechanics of materials sequence as well as an examination of the degree to which (ABET 2000) program outcomes might be derived. The course content review indicated that the course included:

- Considerable application of principles of stress and strain in the analysis of a truss

- Limited applications of these principles in shaft elements in torsion or in beam elements in bending

- Duplicate coverage of topics contained in the third year materials science engineering course: hardness, toughness, and tensile testing.

Regarding program outcomes, the review revealed that the course contained:

- Limited use of computer applications for analysis and design of truss

- No use of web resources

- Considerable hands-on activity related to construction of truss

- Minimal exposure to modern data acquisition systems

- Minimal use of computer applications for data analysis and reporting

- No team based activities 
In addition, polled faculty and students perceived the truss design/build project as the lab centerpiece, the second year rite of passage, the hands-on activity that generated keen student interest and motivation.

\section{Lab Improvement: The Goal, Objectives and Targeted Outcomes}

The ultimate mission of any course is to maximize the likelihood that learning objectives are met. Toward that end, applicable classroom approaches and course characteristics were identified. (The authors currently use some of the following approaches and characteristics):

- Problem based learning: the classroom process that uses "real world" problems to motivate students to identify and apply concepts, principles and information ${ }^{4,6}$

- Experiential learning: learners act and think, not just think, to integrate concrete experience, reflection, generalization (abstract conceptualizations), and experimentations ${ }^{7}$.

- Cooperative team-based learning activities with team and individual deliverables ${ }^{4,8}$

- Self-directed constructive learning with peer teaching and faculty coaching in the delivery of a course $e^{4,9}$

A combination of the first two approaches yields experiential problem based learning. EPBL is the outcome of a 'learner centered' classroom process that uses real work problems as well as fictitious scenarios to motivate students to 'perform' or 'act out' the discovery and application of concepts and information. By doing so, students develop familiar as well as formal understanding of course content. The insertion of individual deliverables into the third bullet serves to hold all students equally accountable to syllabus requirements, while the cooperative team-based learning aspect supports teambuilding skills outcomes. The final bullet incorporates a learner-centered process where students construct a knowledge base as needed using available resources such as other classmates, college staff and the web, and where faculty instructors coach and consult but do not formally lecture.

Based on the above information and the experience of the authors, the following goal and objectives were derived:

- Goal: To develop an experiential problem based learning process that leads to familiar as well as formal understanding of the principles of mechanics of materials.

- Objective: Engage students to actively apply the principles of mechanics of materials by performing the real work of a problem or scenario

- Objective: Promote self-directed learning where student constructs knowledge as needed using available resources and without formal instruction or lecture

- Objective: Integrate active team-based activities and individual accountability to syllabus

The specific outcomes that were sought in the re-tooled laboratory course included:

- Outcome: Formal and familiar knowledge and understanding of the fundamentals of mechanics of materials related to truss, beam and shaft elements.

- Outcome: Familiar knowledge and skill in the use of pc-based applications for analysis and design, data analysis, and reporting.

- Outcome: Formal knowledge in the use of pc-based digital data acquisition control systems in experimentation 
- Outcome: Familiar knowledge and skill in the interaction with a multidisciplinary team

\section{The Course Scenario}

The re-tooled one credit hour MOM lab course was first offered in the spring of 2001 to two sections of 24 students and again in the fall of 2001 to three sections totaling 36 students. Each section met formally once a week for roughly three hours. The first class meeting of the semester was designed to launch the semester long experiential problem based learning lab experience. Students were introduced to the project scenario, the syllabus and other features of the course.

In the scenario, students were asked to imagine they were engineering practitioners employed in a consulting firm, the UTC Mechanics of Materials Lab (MML). In the scenario, MML was retained to provide technical services to a sub-contractor to the International Space Station Project. Specifically, the MML agreed undertake prototype design, construction and evaluations of a structural component.

To minimize the "short-circuiting" of learning, the prototype design problem incorporated into the spring of 2001 scenario differed somewhat from that in the fall of 2001. In the first case, the structural component functioned as a "safety link" intended to fail upon overload conditions to safely protect the space station structure. In the second case, the ultimate capacity of a "hoist support structure" was maximized without exceeding a mass budget. MML also agreed, in the first case, to compare designs having high deflection at failure to those having low deflection and, in the second case, to compare design failure modes. Further, in both cases, MML agreed to consider two material alternatives in the evaluation of prototypes, recently developed WX9 and AK3, space age materials having properties very similar to balsa and acrylic. Again, in both cases, MML agreed to investigate two structural types, the continuous beam (CB) and the open frame truss (OFT).

In addition to design and construction of the prototype components, MML also agreed to conduct evaluative prototype performance testing to verify predicted load vs. deflection and ultimate failure load. Due to budgetary constraints, MML management opted to design, construct and calibrate the necessary load and deflection measuring instrumentations in-house.

Given the scope and quantity of the MML work, the engineering staff was broken down into project teams of three to four members. While each team was responsible to design, build and calibrate one fully functional deflectometer and one load cell, each individual was also responsible to design, build and proof test one truss or beam prototype.

Features of the Course

The re-tooled one credit hour MOM lab course was developed in accordance with the stated goals and objectives. While the EPBL experience revolved around a fictitious scenario, the following real features were incorporated into the lab. Each is discussed briefly below:

- Team project deliverables as well as individual deliverables

- Direct application of principles in the mechanics of materials 
- Design analysis and valuation using MS Excel®

- Hands on application of strain gage and digital DAQ technology

- Analysis of experimental data and reporting using MS Word® and Excel®

- Written engineering communications with extensive use of MS Office ${ }^{\circ}$ features

- Web based course and project communications using Blackboard®

Individual and team deliverables:

Consistent with ABET 2000 outcomes, roughly $60 \%$ of the course work was team based. That is, each team was held accountable and graded for the quality and timeliness of team deliverables and for completing all tasks related to these submittals. The team deliverables included preliminary and "as built" final design reports and calibration reports of load cell and deflectometer instrumentations. In addition to team tasks and deliverables, several individual tasks and submittals were required. Individual tasks included the design and construction of beam and truss prototype structures. Individuals were also responsible for submittal of the preliminary and "as built" final design reports for their respective prototypes as well as the final prototype proof test report.

\section{Application of principles in the mechanics of materials}

While most of the students were co-enrolled in the introductory mechanics of materials lecture, the authors assumed that none had received prior instruction in the principles underlying the design of the load cell, deflectometer, beam or truss. Therefore, just in time mini-seminars were conducted to convey the essential relationships in the mechanics of materials and in the application of MS Excel®. The content of these seminars focused on the principles of stress, strain and deflection of torsional and bending beam members and the truss. Constraints placed on the compression/tension load cell and linear deflectometer called for one to utilize a shaft element in torsion while the other utilized a beam element in bending. This challenged the students wonderfully and similarly challenged the instructors to use care during the learning units to avoid showing any examples or concepts that might be borrowed by students and thereby short-circuit the learning and brainstorming process.

\section{Analysis and evaluation using MS Excel®}

Design and construction of the load cell, deflectometer, and beam and truss prototypes were in accordance with performance and detail specifications prepared by the authors but not included here. Due to the quantity and ranges of parameters, variables and alternatives, the design problem was well suited to spreadsheet analysis. Although the instructors did not provide the specific formulae, the learning units did devote time to guide students in the design and layout of the spreadsheet to take advantage of Excel features such as Goal Seek, Name (variables) and Conditional Formatting.

\section{Hands on application of strain gage and digital DAQ technology}

The introduction of strain gages compelled the instructors to specify a target design strain value of 500-1000 micro-strain to provide sufficient device sensitivity. Team members applied and solder-wired gages after shop fabrication of load cells and deflectometers. A PowerPoint ${ }^{\circledR}$ tutorial and student-student coaching provided sufficient instruction for successful gage application. The strain gage instrumentations were then wired to a National Instruments data acquisition system with VirtualBench GUI. Team members performed the various configuration 
tasks and relied on a step-by-step procedure provided by the instructors as well as studentstudent coaching. Team members, following step-by-step procedures furnished by the instructors, conducted calibration and performance tests.

\section{Analysis of experimental data and reporting using MS Word $\AA$ and Excel $\AA$}

Calibration of the instrumentations required team members to use Excel® Trendline to perform linear regressions of recorded load vs. volt and deflection vs. volt data. The specifications of the calibration report deliverable called for a summary report prepared with MS Word® including a captioned figure of the calibration curve also prepared in MS Excel®.

\section{Written engineering communications with extensive use of MS Office ${ }^{\circledR}$ features}

This engineering course is intended to satisfy a portion of the university's overall general education requirement in written communication. Toward that end, two written deliverables were assigned, the weekly activity reports, or WAR, and the Design Report. The specifications for the WAR required individual students to write a brief narrative account of their project activities, a description of an applied engineering principle, and a personal reflection on the lab experience with recommendations to the instructors. The WAR specifications required students to integrate various features of the MS Office suite of applications. These included inserting engineering formulae using MS Equation ${ }^{\circ}$, captioned figures of graphs prepared in Excel®, digital images, scanned images and CAD drawings, common tables, and tables dynamically linked to an Excel® spread sheet. The WARs were received, graded, returned, revised and re-graded. The Design Report specifications called for the typical content categories: Problem statement, Overview of design process, Applications of engineering principles, Results, Conclusions and Recommendations. The Report specifications also called for inclusion of schematic concept diagrams, spreadsheet analysis and detailed shop drawings. A draft of the Design report was submitted to permit review and approval for construction. The final draft Report reflected the "as built" design.

\section{Web based course and project communications using Blackboard®}

A course website was created to serve as a repository of course materials, a communications center and a collection point of most deliverables. As repository, the website contained the course syllabus, schedule, scenario, specifications, and tutorials. As a communication center, the website was designed to permit the exchange of information, files, and miscellaneous messages between team members, between classmates and between students and instructors. The website also served as a convenient collection point for deliverables. The Blackboard $®$ Digital Drop Box feature proved very useful. Each student was able to "park" any file in his or her private drop box, retrieve it from any networked pc, edit it, re-park it, then when finished, submit the file to the instructor. This feature eliminated the need to copy files to disks and the problem of shipping around large (Mbytes) file documents. The web site was also setup so that team members could "park" files in his or her team's Digital Drop Box and thus permitted team members to share common files.

\section{The Course Schedule}

The course met weekly, 14 times in the semester, for 170 minutes. The course schedule shown in Table 1 was ambitious especially in light of the volume of work reflected in the activities, tasks 
and deliverables. For this reason, the instructors continuously coaxed, coached, and cajoled students to avoid falling behind.

Table 1. Schedule of Activities, Tasks and Deliverables

\begin{tabular}{|l|l|}
\hline Session & Activities, Task \& Deliverables \\
\hline 1 & Introduction, Project Scenario \\
\hline 2,3 & Learning unit: Torsion \& bending: LC \& DG design \\
\hline 4 & LC \& DG: Preliminary Design Report Due \\
\hline 5,6 & LC \& DG Construction \\
\hline 7 & $\begin{array}{l}\text { LC \& DG: Calibration Report Due } \\
\text { Final Design Report Due }\end{array}$ \\
\hline 8,9 & $\begin{array}{l}\text { Learning unit: Truss \& Beams } \\
\text { Truss \& Beam Design }\end{array}$ \\
\hline 10 & Truss \& Beam: Preliminary Design Report Due \\
\hline 11,12 & Truss \& Beam Construction \\
\hline 13 & $\begin{array}{l}\text { Truss \& Beam: Final Design Report Due } \\
\text { Prototype Proof Test }\end{array}$ \\
\hline 14 & Proof Test Report Due \\
\hline
\end{tabular}

Results

Sources of information relied upon to assess the learning outcomes include the specific assessment and grading of the various student and team deliverables, instructor observations and, importantly, student feedback.

\section{Instructor Observations}

Over the semester long period, the instructors observed a growth in the breadth and depth of many students' understanding and familiarity with key principles and concepts in mechanics of materials such as deformations of axial loads, beams in bending, and shafts in torsion and the application of moments of inertia and the stress vs. strain relation. This was observed in the routine instructor/student interaction in the lab and in the office. A similar growth in skill was observed in the use of Excel. Additional observations are noted below.

\section{Student feedback}

Student comments were collected weekly via the WAR. In addition, at the end of semester "Load to Failure" test, instructors asked each student to characterize their lab experience, asked to offer examples of what each "liked most and least", and asked what could be done to make the lab a "better learning experience". The most frequent comment received expressed an appreciation and satisfaction with the hands-on acts of building and using. The second most frequent comment expressed concern about the quantity of the out-of-class time consumed by the course. Roughly $25 \%$ of the students felt the amount of work assigned was not reasonable, the balance, however, felt the time they invested was worth it. The third most frequent reflection (cautiously) suggests that the lab experience was the best yet. The fourth most frequent comment related to the challenges, frustrations and rewards associated with using MS Office applications. Several students expressed new appreciation for Excel® and had already begun to use it in another course. Other comments included: "...liked using the data acquisition system", "Too much 
writing required", "Evening sections need access to the machine shop in the evening", "...liked working with tools in machine shop", "...liked soldering, working with strain gages".

Instructor Reflections and the Future

Were the stated objectives achieved? To what extent were the mechanics of materials learning outcomes attained? While the authors applied no quantified assessment to measure the achievement of learning outcomes, student deliverables such as activity reports, design reports, and informal observations by instructors suggest that students generally developed a deeper understanding of the principles related to the stress, strain and deflection of some but perhaps not all structural elements, i.e. shaft, beam and truss. For example, it was observed in the first offering of the course, that teams delegated tasks to their teammates along the lines of structural elements in such a way that a student would wrestle with a prototype truss design but would have no exposure to the prototype beam. This issue was addressed in the second offering of the course in fall 2001 by requiring all students to develop a functioning Excel® analysis tool for design of a truss and beam before any student was assigned a particular structure type. Predictably, however, this resulted again in a disparity. Therefore in the next course offering in spring 2002, all students will design and construct both truss and beam prototypes. A similar short-circuiting was not observed in the team-based design of load cell and deflectometers, however. We believe this is resulted because the deliverable was one load cell or one deflectometer per team.

Therefore, the subsequent offerings were not changed in this regard.

Did the lab experience actively engage students in the process of self-directed constructive learning? Here the answer is a resounding "yes" and "no". The level of active student engagement was high as reflected by the high successful completion rate of both team and individual tasks, by attendance, by participation, by office traffic, and by after hours use of the labs and shop. However, the degree to which self-directed learning prevailed was not so high. This is thought to be due in part to students' unfamiliarity with the constructivist-learning strategy and in part to a weakened resolve of the instructors to avoid simply "giving up the answer". This remains the authors' single greatest challenge in the execution of the course.

Did the lab experience integrate team activity with individual accountability? The team deliverables required the team to brainstorm, analyze alternative, propose a preliminary design, obtain approval for construction, build, apply strain gages, calibrate, and submit final as build report. While some of these tasks were delegated to individuals, most of these were observed to be broad team efforts that exhibited considerable team interaction. Regarding individual accountability, in the first offering the truss and beam prototype preliminary and final reports were team deliverables while the only individual deliverable was the weekly activity report. In response to student concerns about the tactical difficulty of coordinating team members to prepare the final team report, this was changed to an individual deliverable in the second offering of the course in fall 2001.

Other issues that were raised and that have been targeted for future course offerings include reducing out of class time, increasing availability of the machine shop, and developing PowerPoint ${ }^{\circledR}$ tutorial learning units to replace in-class mini-seminar learning units. 


\section{Acknowledgement}

The authors gratefully acknowledge the generous support provided by the Center for Excellence in Computer Applications (CECA), University of Tennessee at Chattanooga.

\footnotetext{
${ }^{1}$ Henry, Jim, and Charles Knight (2000a) "Improving Laboratories with Internet Controlled Equipment and Internet Student Support," ASEE

Southeastern Meeting, Roanoke, NC, April, 2000.

${ }^{2}$ Henry, Jim, (1995), "LabVIEW Applications in Teaching Controls Systems

Laboratories," ASEE Annual Meeting, Anaheim, CA, June, 1995.

${ }^{3}$ McDonald, G., and Knight, C. "Renovating a Mechanics of Materials Laboratory using Data Acquisition and LabVIEW $^{\circledR}$; ASEE Southeastern Meeting, Roanoke, NC, April, 2000.

${ }^{4}$ Goulet, R., Owino, J., "Mini-lab Round Robin: Alternative to Demonstration Lab", ASEE Southeastern Meeting, Charleston, SC, April, 2001.

${ }^{5}$ Wigal, C., Bailey, R., Goulet, R., "Senior Design”, ASEE Southeastern Meeting, Charleston, SC, April, 2001.

6 The Power of Problem-Based Learning A Practical "How To" for Teaching Undergraduate Courses in Any Discipline Edited by Barbara J Duch, Susan E Groh, Deborah E Allen, Stylus Publishing, LLC, 2001.

${ }^{7}$ Claxton, C. and P. Murrell. Learning Styles: Implications for Improving Educational Practices. ASHE-ERIC Higher Education Report No. 4., Washington, D.C.,1987.

${ }^{8}$ Mourtos, N.J., "The Nuts and Bolts of Cooperative Learning in Engineering", Journal of Engineering Education, ASEE, January 1997, pp. 35-37.
}

RON GOULET, assistant professor mechanical en gineering, joined the UTC engineering faculty in 1998 with over 20 years of professional experience. Following the award of B.S. in civil engineering from Northwestern University in 1976, he held various engineering positions serving the power, legal and insurance industries in Chicago, Pittsburgh, and Maine. Goulet received a Ph.D. in Engineering from the University of New Hampshire in 1997 in the field of fracture mechanics. Dr. Goulet's primary research interest includes the application of 3D vision based displacement measurement techniques in experimental mechanics.

JOSEPH OWINO, is an assistant professor in civil engineering at UTC. He received his Ph.D. in civil engineering from Georgia Institute of Technology in 1998. Prior to attending graduate school, Dr. Owino was a Lecturer at the University of Nairobi. Dr. Owino was also employed as an offshore design engineer at Shell Oil Company for 6 years immediately after he obtained his M.S degree in civil engineering from Howard University. Dr. Owino's primary research interest includes Structural Modeling, Finite Element Analysis and NDE of Bridges (Laboratory and Field Testing). 